\title{
Tipografia em cartazes de cinema como representação de identidade e storytelling: um estudo de caso do estúdio Ana França Design
}

Typography in movie posters as representation of branding and storytelling: a case study of Ana França Design studio

KRUPAHTZ, Juliana; acadêmica; Curso de Desenho Industrial; Universidade Federal de Santa Maria juliana.krupahtz@gmail.com

MATTÉ, Volnei; Prof. Dr.; Curso de Desenho Industrial; Universidade Federal de Santa Maria volnei.a.m@gmail.com

\section{Resumo}

A tipografia é um elemento central do design gráfico e sua utilização nos cartazes cinematográficos é fundamental para a comunicação efetiva da mensagem. Sendo assim, este artigo tem como objetivo compreender possíveis relações entre tipografia e cartazes de cinema, atuando também como ferramenta de storytelling e identidade dos filmes. Para isso, foi estruturada uma metodologia de análise gráfica dos cartazes dividida em três fases, com foco na tipografia. Para atingir o seu objetivo, foram feitas as análises de três cartazes, dos filmes Estômago (2007), Elis (2016) e Hoje Eu Quero Voltar Sozinho (2014), todos de criação do estúdio Ana França Design, do Rio de Janeiro.

Palavras Chave: cartaz; tipografia; cinema.

\begin{abstract}
Typography is an important element of graphic design and in movie posters, it's fundamental for an effective communication of the message. This way, this article's objective is to understand the possible relations between typography and movie posters, also acting as a tool for storytelling and movie branding. So, it was structured a methodology of graphic analysis to movie posters, divided in three steps, with typography as the main subject. To reach its objective, it was analyzed three posters, from the movies Estômago (2007), Elis (2016) and The Way He Looks (2014), all of them designed by the studio Ana França Design, from Rio de Janeiro.
\end{abstract}

Keywords: poster; typography; cinema. 


\section{Introdução}

O design gráfico está presente na história do cinema desde o seu início. A principal peça é o cartaz, inicialmente das companhias de teatro e depois sendo o destaque na divulgação impressa de filmes em cinemas. O cartaz cinematográfico é uma importante ferramenta de divulgação se bem utilizada, e também de representação narrativa. Assim como o trailer do filme, ele apresenta o contexto do roteiro só que por meio de elementos estáticos.

Um dos principais elementos visuais presentes no cartaz é a tipografia, que possui potencial expressivo. O objetivo desta pesquisa é compreender algumas possíveis relações entre o uso da tipografia em cartazes de cinema como representação da identidade e storytelling dos filmes a partir de uma metodologia de análise de cartazes estruturada em três etapas. Foram analisados cartazes dos filmes Estômago (2007), Elis (2016) e Hoje Eu Quero Voltar Sozinho (2014), todos de criação do estúdio Ana França Design, situado no Rio de Janeiro, Brasil.

A análise prática dos cartazes foi feita a partir da metodologia apresentada e com reflexões sobre como o conhecimento específico de tipografia, sua forma, classificação e cor, pode resultar em uma melhor aplicação nos títulos de filmes. Ao final, são feitas considerações sobre o método utilizado e narrativa visual tipográfica.

\section{Cinema em cartaz}

Os cartazes fazem parte da história do cinema desde o seu início. Trazidos dos circos e teatros itinerantes que utilizavam as peças gráficas como forma de divulgação de suas atrações (FULLER-SEELEY, 2012, p. 399), os primeiros cartazes de cinema apresentavam somente o título das obras e eram considerados peças de divulgação do local de exibição dos filmes e não dos filmes em si, como o exemplo da primeira sessão pública e paga de cinema, que aconteceu em 1895 no Grand Café em Paris, quando os irmãos Lumière demonstraram o seu novo equipamento, o cinematógrafo (MASCARELLO, 2006). Todavia o filme que iniciou um novo padrão gráfico no cinema foi justamente uma das películas exibidas nesta sessão, L'Arroseur Arrosé (1895), de Louis Lumière, foi o primeiro a possuir um cartaz exclusivo e individual de uma folha (Figura 1). Porém, ao contrário das peças atuais, os primeiros cartazes focavam em ilustrar a nova experiência de assistir a filmes em salas de cinema, mostrando o público e a nova tecnologia. De acordo com Schmidt (2016), as peças gráficas cumpriram um papel tão importante na história do cinema que a expressão "em cartaz" acabou tomando o mesmo significado de "em exibição".

Figura 1 - Cartaz do filme L'Arroseur Arrosé (1895), de Louis Lumière.

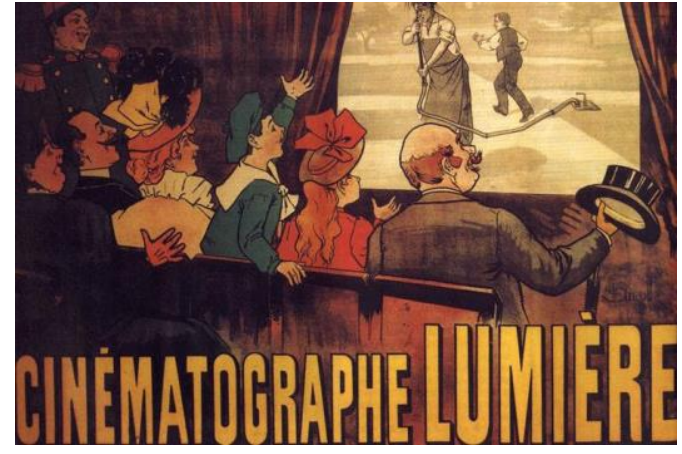

Fonte: Campaign (2016). 
A tipografia é um elemento importante dentro da composição visual de um cartaz, e no universo dos cartazes de cinema não poderia ser diferente. Moles (1974) relata que o cartaz é um "escândalo visual", deve ser visto, não olhado, é de leitura instantânea, e por isso deve chamar a atenção. No cartaz do filme L'Arroseur Arrosé (1895), já é possível perceber o destaque dado à tipografia, que até então aparece representando o nome do cinema dos irmãos Lumière e não o nome dos filmes.

Do início dos cartazes para os anos 50 e 60, não há como não mencionar o nome de Saul Bass, designer e cineasta que ficou conhecido pelo seu trabalho de Design gráfico no cinema. Trabalhou com grandes nomes como Otto Preminger, Alfred Hitchcock, Stanley Kubrick e Martin Scorsese (HEITLINGER, 2014). Bass utilizava da tipografia como recurso nas suas criações, fazendo com que multiplicasse o seu potencial comunicacional ao não ser aplicada somente como texto, mas também como figura e imagem. Em 1955 fez um de seus mais conhecidos trabalhos, o cartaz do filme The Man With the Golden Arm (1955), do diretor Otto Preminger (TAÚ; OLIVEIRA; NESTERIUK, 2015, p. 343). Além de cartazes, Bass também produzia as aberturas dos filmes, e seu trabalho com a tipografia na área é referência na área até hoje.

No cartaz do filme Bunny Lake is Missing (1965) (Figura 2) é possível perceber a tipografia do cartaz sendo utilizada para intensificar a mensagem do título do filme, com o gradiente de cor, passa a sensação de desaparecimento e cria expectativa em torno da história que será contada.

Figura 2 - Cartaz do filme Bunny Lake is Missing (1965), de Otto Preminger.

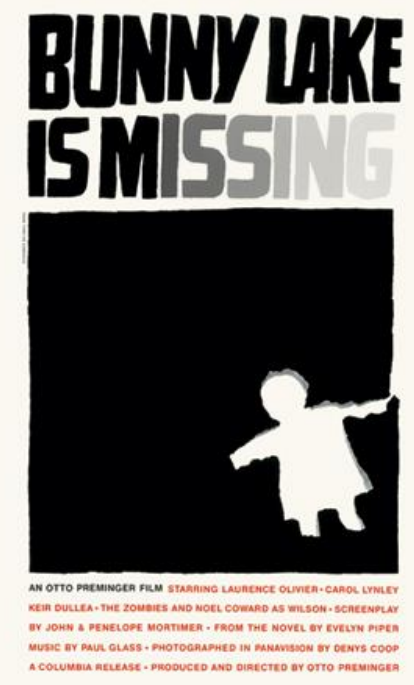

Fonte: Campaign (2016).

Desde o seu início, o cartaz de cinema pode ser considerado uma peça publicitária, devido a isso o trabalho de Bass é tão relevante dentro da área do design, pois rompeu com a estética dos cartazes da época e trouxe o conhecimento técnico da área, principalmente da Bauhaus ${ }^{1}$. Sua

\footnotetext{
${ }^{1}$ Saul Bass teve grande influência da Bauhaus por ter sido aluno de Gyorgy Kepes, um dos fundadores da escola (TAÚ; OLIVEIRA; NESTERIUK, 2015, p. 343).
} 
influência foi fundamental para mudar a maneira como os cartazes eram construídos graficamente, que normalmente davam destaque aos atores principais ou a alguma cena do filme. Bass pensava na identidade visual do filme, mantendo coerência com as outras peças e também com elementos-chave da obra (TAÚ; OLIVEIRA; NESTERIUK, 2015).

\subsection{Storytelling e marca cinematográfica}

O designer Tomasz Opasinski, em entrevista para o site da Gnomon ${ }^{2}$ (2016), afirma que o cartaz é uma ferramenta de venda, é artístico, mas não uma obra de arte. Opasinski diz ainda que um cartaz abstrato, por exemplo, pode ser bonito, mas se ninguém entender, não leva a lugar nenhum. Além disso, destaca que o objetivo de um cartaz de cinema é guiar o público para o ponto de virada do filme, o centro da história, e então, criar a curiosidade do que irá acontecer.

Dessa forma, Tomasz defende o cartaz como um elemento que também ajuda a contar a história do filme, que pode apresentar elementos para atrair o público para o cinema e também fazer referências a outras peças que compõem a divulgação cinematográfica, como os trailers, que tem a função de divulgar o filme em vídeos de média de dois minutos de duração, onde aparecem pontos essenciais da narrativa. Da mesma maneira, o cartaz deve então apresentar elementos da narrativa que entreguem a temática ou momentos do roteiro. A tipografia pode ser utilizada como um desses elementos, como foi no caso do cartaz de Bunny Lake is Missing (1965).

Além de um elemento de representação do roteiro do filme em si, a tipografia também é um recurso de expressão de personalidade. Cada filme é um produto da indústria cinematográfica e possui um conceito de criação, recebe investimento em divulgação, marketing e publicidade, assim como espera-se que gerem retorno financeiro, filmes comunicam, geram valor e transmitem conceitos (VOGELMAN; KIRINUS; MAFALDA, 2014).

\subsection{O estúdio Ana França Design}

O mercado cinematográfico está constantemente crescendo e investe muito na divulgação de seus produtos. De acordo com a Reuters (2010), nos EUA e Canadá, para cada um dólar gasto na produção de um filme, entre 51 e 58 centavos são investidos em marketing e lançamento. 0 cartaz de cinema pode ser considerado a principal peça gráfica de divulgação de um filme e juntamente com a produção dos filmes, cresce também a produção de cartazes. Somente em 2016 foram lançados 457 títulos, comparados aos 317 de 2009. No Brasil, esse número subiu de 84 para 142 em títulos de lançamento nacional (OCA, 2016).

Nesse contexto, o mercado do cinema brasileiro além de acompanhar o crescimento mundial, também se destaca dentro dele. O longa-metragem Os Dez Mandamentos - O Filme alcançou a marca de maior público do ano de 2016, com mais de 11 milhões de ingressos vendidos. Por isso, como forma de estudar, incentivar e promover a produção nacional, foi escolhido trabalhar somente com filmes feitos no Brasil, e como forma de padronização da amostragem, foram selecionados cartazes de um mesmo estúdio.

Ana França Design é um estúdio de design carioca dedicado a indústria cinematográfica, fundado em 2009. O estúdio possui um vasto histórico de criações e, para esta pesquisa, foram selecionados três trabalhos, que possuíam uma amostragem diferenciada em relação a tipografia. Serão analisados os cartazes dos filmes Estômago (2007), Elis (2016) e Hoje eu Não Quero Voltar

\footnotetext{
${ }^{2}$ Gnomon é uma escola de efeitos visuais, situada na Califórnia, EUA.
} 
Sozinho (2014).

\subsection{Análise dos cartazes}

A análise realizada foi descritiva e interpretativa, dividida nas seguintes fases: (i) apresentação do filme e conceito; (ii) estrutura e ordem de leitura; e (iii) tipografia - forma, classificação e cor (Figura 3). Por fim, se apresenta uma reflexão sobre a influência da tipografia como elemento representativo da narrativa visual do respectivo cartaz.

Figura 3 - Estrutura da metodologia.

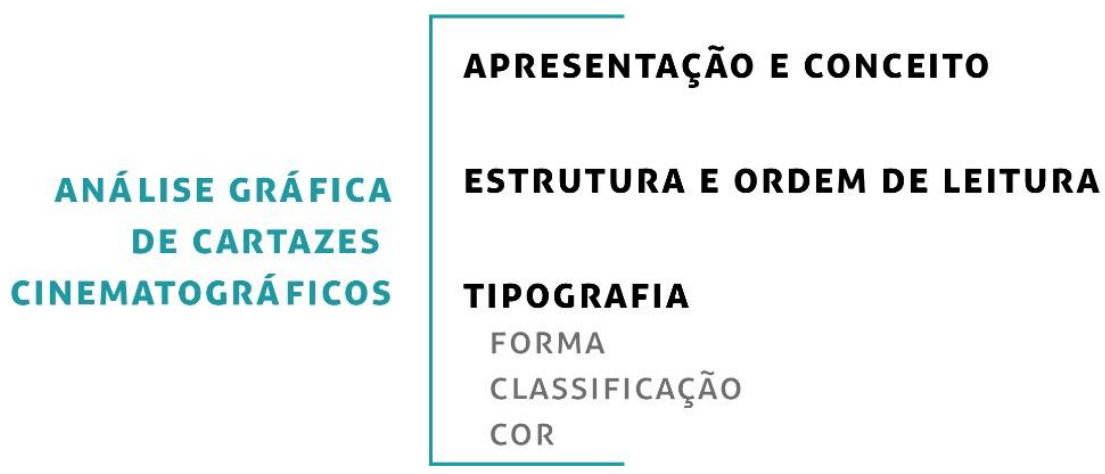

Fonte: Elaborado pela autora.

O propósito desta análise é de propor uma compreensão geral do contexto de criação dos cartazes, com foco na escolha da tipografia. Por isso há um número reduzido de fases metodológicas e também uma maior segmentação na parte de tipografia. No início foi feita uma apresentação de cada filme, para que pudesse haver entendimento sobre o roteiro e assim estabelecer conexões com a narrativa visual proposta pelo cartaz. Nesta fase também foi apresentada uma sinopse dos filmes e identificados os atores principais e coadjuvantes. $\mathrm{Na}$ segunda fase a estrutura do cartaz é analisada, além da ordem de leitura dos elementos principais. Para isso, primeiramente foram desenhadas possíveis linhas-guia que auxiliaram na composição inicial do cartaz durante o seu desenho, com um grid de base, é possível perceber quais elementos foram propositalmente deixados em destaque e também a relação da tipografia com o restante da composição. A terceira e última fase divide-se em três etapas, na primeira a forma da tipografia do título do filme é analisada, utilizando fatores como contraste, desenho, espaçamento e ângulos dos caracteres. Logo na sequência é feita uma possível classificação histórica do tipo, ou em um grupo de estilo tipográfico, para isso, também podem ser utilizadas outras famílias tipográficas como referência para análise. Como encerramento, é feita uma contextualização de paleta cromática ou cor aplicada na tipografia.

Devido à grande quantidade de cartazes e filmes produzidos mundialmente, é importante salientar que esta pesquisa não tem como objetivo traçar padrões sobre a aplicação da tipografia, principalmente por utilizar-se de uma amostragem muito baixa de cartazes. Tem-se como objetivo apenas compreender algumas relações do uso da tipografia em cartazes de cinema como representação da identidade e storytelling dos filmes a partir da metodologia citada anteriormente. 


\subsubsection{Estômago (2007)}

Um filme com direção de Marcos Jorge, lançado no ano de 2007, Estômago (Figura 4) conta a história de Raimundo Nonato, protagonista interpretado por João Miguel Serrano Leonelli, e não possui uma narrativa cronológica linear. A história de Raimundo, também chamado de Alecrim, começa na cadeia e alterna entre passado e presente, com ele narrando como era a sua vida antes de ser preso, e com isso cria-se a curiosidade de descobrir como a personagem acabou por estar naquele lugar. Ele conta que começou trabalhando como cozinheiro em um bar, então foi para um restaurante italiano e depois passa a cozinhar também na prisão. A trama conta ainda com outros personagens importantes, como a personagem Íria, uma prostituta com quem Raimundo acaba se envolvendo, Bujiú e Etecetera, que Nonato conhece na prisão e Giovanni, dono do restaurante italiano que percebe o talento para culinária do protagonista e passa para ele seus ensinamentos de gastronomia (IMDB, 2007).

Figura 4 - Cartaz oficial do filme Estômago, estrutura e ordem de leitura.
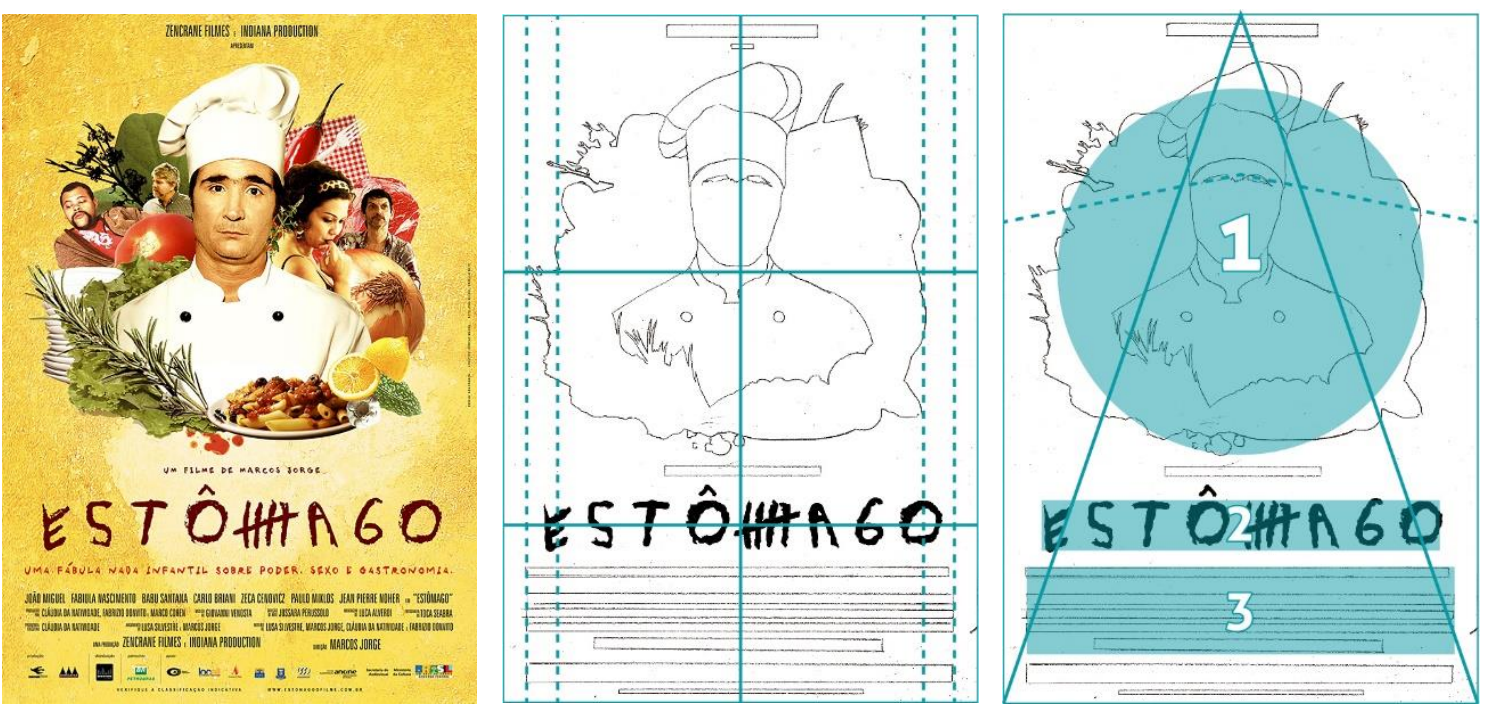

Fonte: Elaborado pela autora com base em Ana França Design (2007).

Baseando-se então na trama do filme, pode-se traçar três elementos centrais da narrativa, apresentados também no slogan, poder, sexo e culinária. Esses elementos são fundamentais para a análise visual do cartaz, já que um dos objetivos do mesmo é não entregar o desenrolar da história - qual o crime cometido pelo protagonista - e sim, criar a curiosidade no público de querer descobrir o mistério.

Em relação a estrutura e ordem de leitura (Figura 4) do cartaz de Estômago (2007), foram traçadas as principais linhas-guia da composição. É possível perceber um alinhamento centralizado de todo o cartaz, com a disposição dos elementos principais em pirâmide, tendo o maior destaque a imagem do ator principal, João Miguel. Em segundo lugar, aparecem os outros elementos na fotografia, como os atores coadjuvantes de maior relevância na trama e também a tipografia, situada logo abaixo. Em um terceiro nível aparecem os elementos tipográficos de menor escala, como o slogan do filme - "Uma fábula nada infantil sobre poder, sexo e gastronomia" -, os 
créditos e os apoiadores.

A fotografia também revela muitos elementos da narrativa do filme, trazendo sutilezas na composição da montagem central. Traçando-se duas linhas a partir do ângulo das sobrancelhas do protagonista, temos a posição dos atores coadjuvantes. Além disso, a expressão do ator central ajuda a criar um conceito sobre a própria personagem, que tem como característica ser uma pessoa simples e a expressão do mesmo ajuda a transmitir essa imagem. Todavia, logo abaixo da fotografia dele, aparece uma mancha de sangue, próxima ao nome do diretor - um ponto chave da leitura do cartaz -, ou seja, é algo que foi colocado em uma posição para que fosse visto, mesmo que sutilmente, e lembra ao espectador que há um ponto de tensão na trama.

A tipografia é o segundo elemento de mais destaque no cartaz, vindo logo abaixo da fotografia. Na análise de forma pode-se identificar uma letra manuscrita, totalmente em caixa alta, com arestas irregulares e sem grande contraste, remetendo uma escrita em parede irregular feita por instrumento de ponta redonda de maneira rudimentar (Figura 5). O conceito do filme se destaca no desenho da letra " $M$ ", que foi substituída pelo símbolo criado a partir da contagem de dias que presidiários fazem durante a permanência na cadeia. Com este símbolo, a tipografia reforça sua presença como elemento narrativo, sendo aquele com maior destaque visual que ilustra a presença do contexto de prisão no roteiro do filme. Quanto a classificação, esse título pode ser entendido como um tipo display, já que tem caráter decorativo e não se encaixa propriamente em um período histórico tipográfico. As letras não possuem um mesmo eixo e também variam no espaçamento entre caracteres.

Figura 5 - Título do filme Estômago (2007).

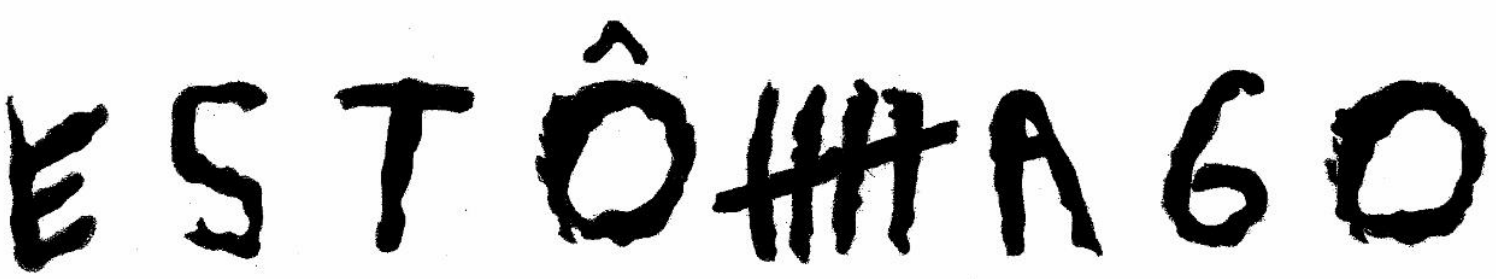

Fonte: Elaborado pela autora com base no cartaz oficial do filme.

A paleta de cores do cartaz como um todo traz combinações de cores análogas, unindo o verde ao amarelo e o amarelo ao vermelho, sem causar grande contraste entre os tons. A tipografia do título principal, em vermelho escuro, quase em um tom de marrom, pode ser representativa do drama da narrativa central, possivelmente remetendo às manchas de sangue, ou apenas para ilustrar um aspecto de sujo, como forma de reforçar a tipografia inspirada nas letras feitas em paredes de penitenciárias.

Estômago traz seus dois eixos de narrativa do roteiro ilustrados em dois elementos com grande peso na composição, o título e a fotografia. A tipografia do cartaz representa o período narrativo da prisão - tempo presente - enquanto a fotografia representa a gastronomia - tempo passado. Além disso, pela análise pode-se inferir que devido a complexidade da montagem fotográfica, a estrutura do cartaz foi feita de maneira mais limpa, tendo uma ordem de leitura vertical, de cima pra baixo, e utilizando uma paleta de cores sem tanto contraste. A textura do 
fundo também, que é suave e em uma cor clara, ajuda a destacar o título do filme e a dar maior legibilidade ao slogan e outras informações menores, que poderiam ser de difícil compreensão caso o fundo fosse muito poluído visualmente.

\subsubsection{Elis (2016)}

O filme Elis retrata a vida da cantora brasileira Elis Regina, tem direção de Hugo Prata e Andreia Horta no papel da protagonista. De maneira resumida, o longa mostra desde quando Elis deixa o Rio Grande do Sul e passa a morar no Rio de Janeiro, a fim de obter sucesso em sua carreira como cantora, e encerra com a sua morte, mostrando os momentos de maior destaque durante sua vida, como acontecimentos históricos envolvendo o governo do país, seus casamentos, filhos e apresentações mais grandiosas. Um dos principais pontos - até mesmo da divulgação - do filme foi a performance da atriz principal e a sua semelhança com a cantora. Nos enquadramentos isso ainda é feito com destaques em cenas nas quais a atriz representa muito bem os trejeitos, a voz e até o timbre de Elis.

Devido a isso, pode-se compreender um dos possíveis motivos para o destaque da fotografia dentro do cartaz, que utiliza inclusive uma imagem muito semelhante à de um trecho do filme, que também ilustra o nome da atriz principal no trailer oficial (Figura 6). Nessa imagem, o sorriso, o cabelo e a postura de Andreia enfatizam a semelhança com Elis Regina, o que em uma biografia é muito significativo para atrair atenção do público, pois demonstra fidelidade com a história verídica.

Figura 6 - Frame do trailer oficial do filme Elis (2016).

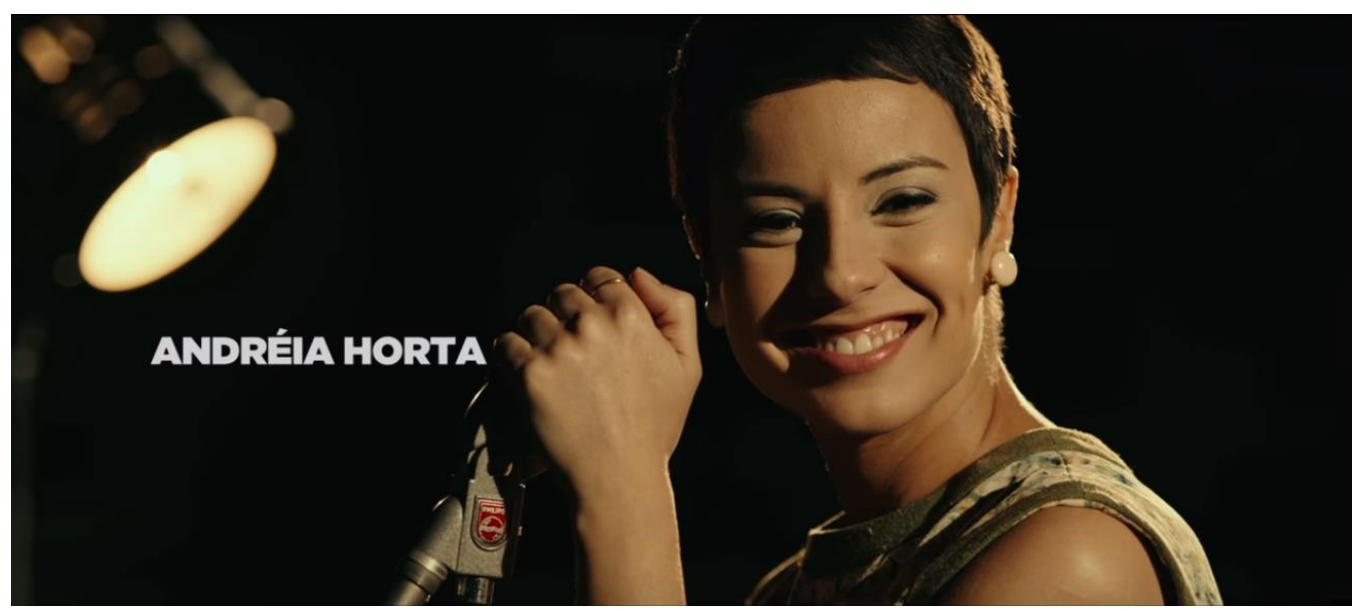

Fonte: Downtown Filmes (2016).

A estrutura do cartaz de Elis (Figura 7), da mesma maneira do cartaz de Estômago (2007) possui um alinhamento principal centralizado, e destaque na fotografia e no título do filme. No entanto neste cartaz, a tipografia ganha mais destaque, sendo o primeiro elemento na ordem de leitura, fazendo com que o fluxo siga de baixo para cima e então retorne para o rodapé. O rosto da atriz principal ganha bastante destaque na peça, não aparecendo nenhum outro ator coadjuvante, o que reforça o apelo da biografia e da verossimilhança do filme. No canto superior esquerdo, aparece o elemento que une toda a narrativa do cartaz que é a iluminação, trazendo o conceito de holofote, palco e fama, o que remete ao sucesso da carreira de Elis Regina. Ao traçar uma reta a partir do canto superior esquerdo, encontra-se o centro do rosto da atriz e também o eixo central 
da tipografia do título do filme.

Figura 7 - Cartaz oficial do filme Elis, estrutura e ordem de leitura.
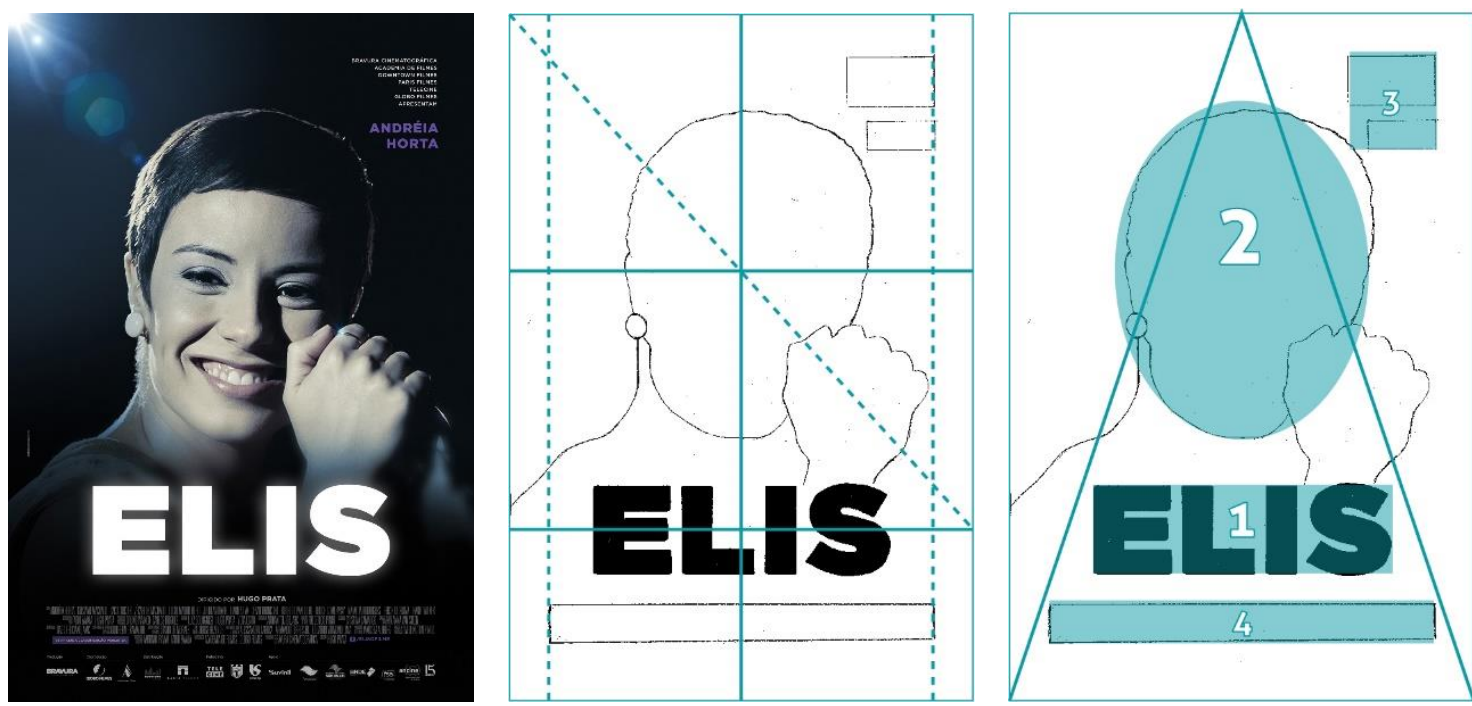

Fonte: Elaborado pela autora com base em Ana França Design (2016).

A fonte tipográfica utilizada em Elis (Figura 8) pode ser classificada como uma fonte grotesca, sem serifa. Ela possui um espaçamento maior, o que faz que ocupe mais espaço horizontal no cartaz e seja adequada ao filme de título curto. A fonte utilizada foi a Gotham, no seu peso Ultra, desenhada por Tobias Frere-Jones nos anos 2000.

Figura 8 - Título do filme Elis (2016) e sobreposição da fonte Gotham Ultra.
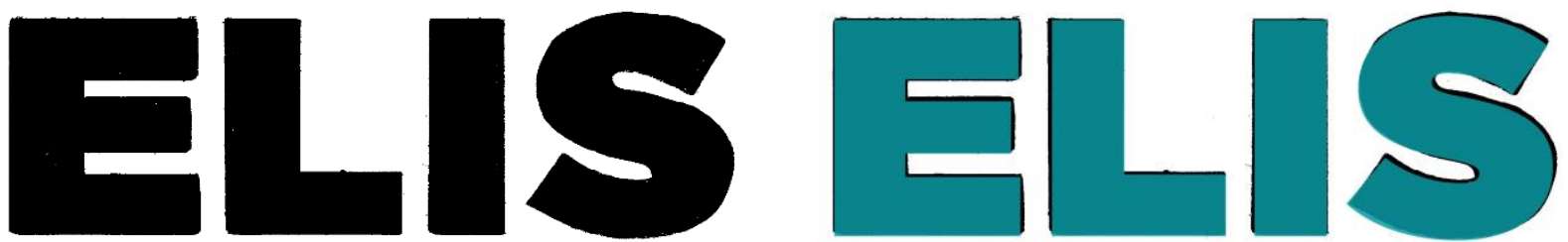

Fonte: Elaborado pela autora com base no cartaz oficial do filme.

O mesmo conceito gerado a partir da iluminação também aparece na tipografia do título, que possui uma área branca ao redor do limite dos caracteres, dando o aspecto de que o nome da artista também é uma fonte de luz. Esse efeito, juntamente com a forma do tipo, que é pesada e geométrica, faz com que a tipografia seja o elemento que mais se destaca na composição.

Além de transmitir a ideia central do filme, a tipografia no cartaz de uma biografia tem a responsabilidade de transmitir a personalidade daquele que é retratado no filme. Elis Regina ficou conhecida - e essa característica também é enfatizada no filme - por ter uma personalidade forte e marcante, quase uma teimosia em conseguir o que deseja. Uma tipografia de traços finos, muito contrastada não iria ser adequada à protagonista, por isso a fonte escolhida é bem-sucedida em 
representar já no instante inicial, mesmo para aqueles que não tem conhecimento sobre a cantora, que ela possui uma personalidade marcante, porém iluminada.

\subsubsection{Hoje Eu Quero Voltar Sozinho (2014)}

Com direção de Daniel Ribeiro, o longa-metragem é baseado no curta do mesmo diretor Eu Não Quero Voltar Sozinho, de 2010. O filme conta a história do protagonista Leonardo (Ghilherme Lobo), um adolescente com deficiência visual que possui uma mãe superprotetora, que, ao conhecer Gabriel (Fabio Audi), começa a descobrir sentimentos novos e aprender mais sobre si mesmo e sua sexualidade.

Tendo como base um elenco predominantemente adolescente, e tratar sobre conflitos e questões dessa fase da vida, nota-se a preocupação de ter a representação da faixa etária com elementos escolares que representem bem o cenário da trama. No cartaz, os atores principais, Ghilherme Lobo e Fabio Audi, aparecem em destaque com os uniformes escolares e os outros elementos, incluindo a tipografia, remetem diretamente ao manuscrito, imperfeito de uma letra no caderno da sala de aula, com traços circulares destacando partes importantes e flechas com anotações paralelas.

A estrutura do cartaz (Figura 9) que novamente traz como linhas principais o alinhamento triangular, desta vez centraliza vertical e horizontalmente o título do filme, que ganha grande destaque na composição. Seguindo o mesmo princípio dos outros cartazes analisados, o protagonista é o primeiro elemento na ordem de leitura, mas tem peso muito parecido na composição com o título, que vem logo na sequência. Também como elemento importante, há o rosto do ator coadjuvante, que aparece após o título e direciona o olhar ao texto do rodapé, quase induzindo a leitura dos créditos, que aparecem na sequência.

Figura 9 - Cartaz oficial do filme Hoje Eu Quero Voltar Sozinho, estrutura e ordem de leitura.
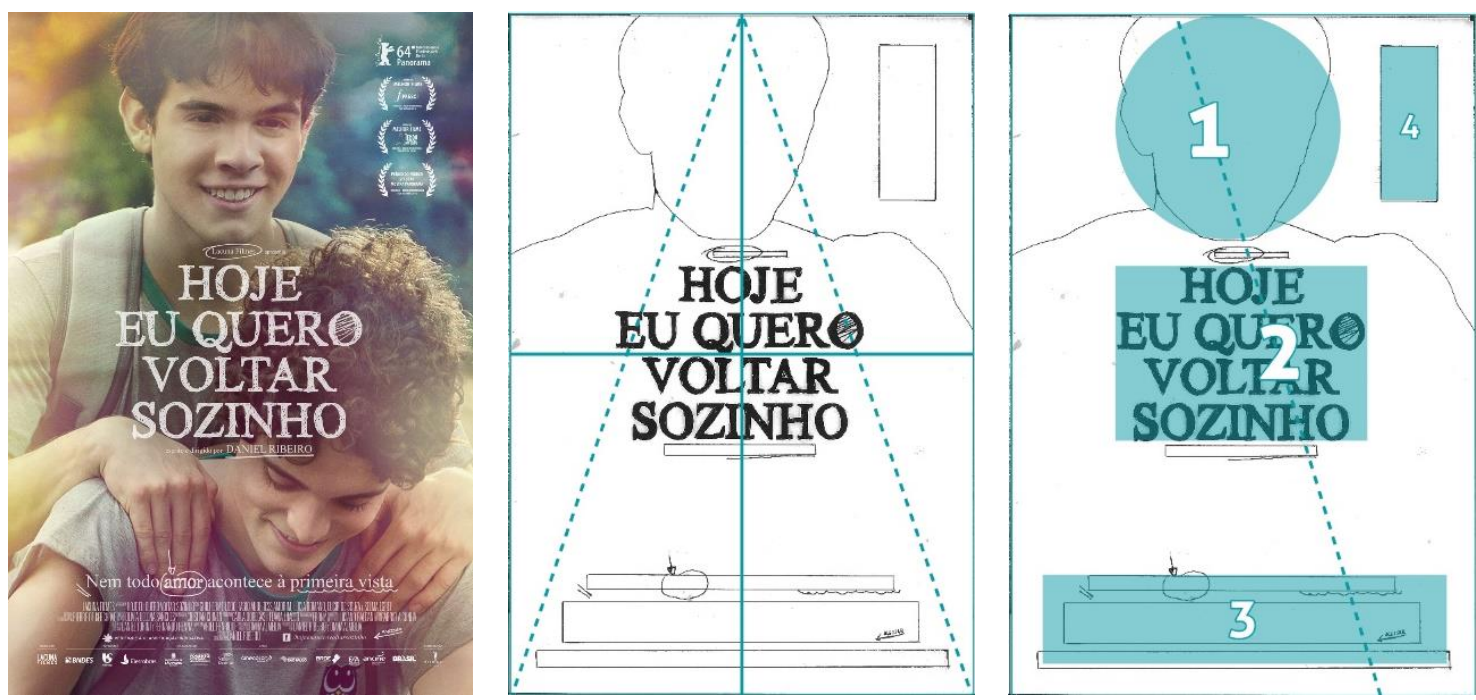

Fonte: Elaborado pela autora com base em Ana França Design (2016).

Em relação à tipografia do cartaz (Figura 10), como já mencionado, é visível a sincronia com os elementos que remetem ao roteiro do filme destinado ao público adolescente. Ao observar-se 
o título com mais detalhes, é possível também perceber que provavelmente o desenho das letras foi feito manualmente nessa peça, diferentemente dos outros cartazes analisados, pois cada letra é diferente entre si, as formas não são perfeitas e é justamente o seu formato, combinado com o preenchimento irregular, como se fosse pintado a caneta esferográfica ou giz, com os traços que fogem do contorno dos tipos, como no caso da letra "O" ao final de "QUERO" e da letra " $A$ " em "VOLTAR" que fazem com que os tipos se misturem muito melhor a fotografia em tons de magenta e verde, que dá uma expressão romântica ao cartaz.

Figura 10 - Título do filme Hoje Eu Quero Voltar Sozinho (2014).

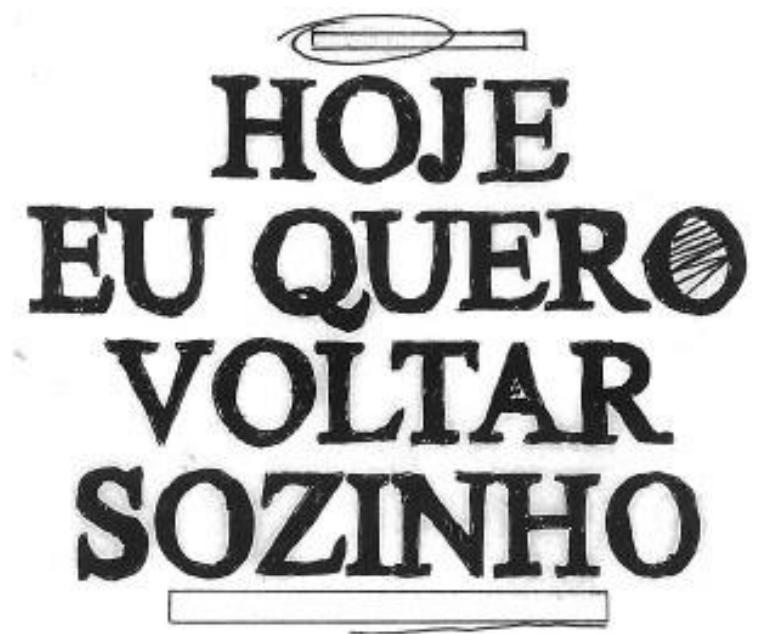

Fonte: Elaborado pela autora com base no cartaz oficial do filme.

Os tipos desenhados possuem serifas bem rústicas, lembrando os tipos egípcios que possuem uma espessura semelhante, com pouco ou quase nenhum contraste entre as hastes verticais, horizontais e as serifas. Esse estilo tipográfico também ajuda com que o título seja um dos elementos de destaque, pois acrescenta peso à composição. Além disso, foi optado por organizar as palavras quase de maneira vertical, de maneira que o título se tornou um bloco quadrado no centro da página. Possivelmente para que não ficasse tão desproporcional na composição, foi escolhida a cor branca ao invés de outra para amenizar o contraste entre os elementos.

O cartaz do filme de Daniel Ribeiro possui uma composição interessante e que atinge seu objetivo ao indicar o público e o tema do qual o longa se trata. A tipografia é utilizada como elemento principal e bem estruturada como elemento ilustrativo e narrador da história ao se misturar com traços para além das formas dos tipos. Além disso, a ordem de leitura criada posicionando o título entre os rostos dos protagonistas faz com que seja quase impossível não notar a tipografia como elemento de destaque.

\section{Considerações finais}

Por meio dos estudos teóricos e das análises feitas, pôde-se perceber como a tipografia é um elemento de grande destaque na composição de cartazes de cinema, pois o título do filme é uma das informações centrais da peça. No entanto, assim como os outros elementos visuais da 
composição, ela pode e deve ser utilizada como recurso narrativo para auxiliar a transmitir a mensagem do filme. Por meio de sua forma, classificação e cor é possível a identificação de elementos que ilustram a personalidade do tipo, fazendo com que a escolha de tipografias na hora de um projeto de cartaz cinematográfico seja pensada também no planejamento.

Saul Bass conseguiu quebrar com muitos padrões nos projetos de cartazes cinematográficos, dando grande destaque para a tipografia em composições minimalistas. Atualmente, ainda é muito comum o uso de atores para representação dos filmes em cartazes, principalmente no contexto do cinema brasileiro, abordado por esta pesquisa. Por causa disso, é comum que o cartaz de escolha do estúdio de criação - de design - seja diferente daquele escolhido pela produtora do filme, essa opção é frequentemente chamada de designer's cut. Nos cartazes analisados neste artigo, todos exibem na fotografia o rosto do ator principal, e Estômago ainda inclui quatro coadjuvantes, o que pode tornar a composição muito poluída.

O objetivo de compreender algumas relações do uso da tipografia em cartazes de cinema como representação da identidade e storytelling dos filmes pode ser cumprido por meio da metodologia utilizada, que foi a maior contribuição desta pesquisa, juntamente com a reflexão sobre o tema que não é muito frequente na bibliografia. Com um mercado de audiovisual e cinema tão crescente no país, é interessante que mais pesquisas na área, relacionando com o design e tipografia possam ser feitas, para que novos caminhos sejam abertos e haja conteúdo específico desta área tão relacionada à comunicação.

\section{Referências}

CAMPAIGN. History of advertising: the first film poster. Disponível em:

<https://www.campaignlive.co.uk/article/history-advertising-no-173-first-film-poster/1400291>. Acesso em: 27 nov. 2017.

FULLER-SEELEY, K. Storefront theater advertising and the evolution of the american film poster. In: GAUDREAULT, A.; DULAC, N.; HIDALGO, S. A companion to early cinema. 1. ed. Chichester, UK: John Wiley \& Sons, 2012, p. 398-419.

GNOMON. 15 things you need to know to design hollywood movie posters. Disponível em: <https://www.gnomon.edu/blog/15-things-you-need-to-know-to-design-posters-for-hollywoodmovies>. Acesso em: 7 out. 2017.

HEITLINGER, P. Saul Bass: Designer gráfico e cineasta, trailers de filmes. Disponível em: <http://tipografos.net/designers/bass-saul.html>. Acesso em: 7 out. 2017.

IMDB - INTERNET MOVIE DATABASE. Estômago. Disponível em: <http://www.imdb.com/title/tt1039960/?ref_=nmbio_mbio>. Acesso em: 4 dez. 2017.

MASCARELLO, F. (Org.) História do cinema mundial. Campinas, SP: Papirus, 2006.

MOLES, A. O Cartaz. 2 ed. São Paulo: Editora Perspectiva, 1974.

OCA - OBSERVATÓRIO BRASILEIRO DO CINEMA E DO AUDIOVISUAL. Anuário estatístico do cinema brasileiro 2016. Ministério da Cultura. Brasília, DF: Agência Nacional do Cinema, 2016. Disponível em: < https://oca.ancine.gov.br/sites/default/files/repositorio/pdf/anuario_2016.pdf>. Acesso em: 5 nov. 2017. 
REUTERS. How much does movie marketing matter? Disponível em:

<http://www.reuters.com/article/us-industry/how-much-does-movie-marketing-matteridUSTRE65A13Q20100611>. Acesso em: 12 nov. 2017.

SCHMIDT, L. R. Vanguarda, cartaz e cinema: uma aproximação entre a escola polonesa e saul bass. Blucher Design Proceedings, 2016. v. 9, n. 2, p. 412-423. Disponível em:

<http://pdf.blucher.com.br.s3-sa-east-1.amazonaws.com/designproceedings/ped2016/0036.pdf>. Acesso em: 9 out. 2017.

TAÚ, M.; OLIVEIRA, M.; NESTERIUK, S. Design gráfico no cinema: Saul Bass. Educação gráfica, 2015. v. 19, n. 3, p. 336-352. Disponível em:

<https://s3.amazonaws.com/academia.edu.documents/42578329/26_DESIGN-GRAFICO-NOCINEMA_336_3521.pdf?AWSAccessKeyld=AKIAIWOWYYGZ2Y53UL3A\&Expires=1507596567\&Sign ature=YLVBgjXajCU6euoDznmjYFLndpE\%3D\&response-content-disposition=inline\%3B filename\%3DDesign_Gr>. Acesso em: 9 out. 2017.

VOGELMAN, L. G.; KIRINUS, G. G.; MAFALDA, A. De Star Wars a Indiana Jones: a construção da marca cinematográfica através dos cartazes de filmes de George Lucas. Blucher Design

Proceedings, 2014. v. 1, n. 2, p. 1-9. 